\title{
Trophic support delays but does not prevent cell-intrinsic degeneration of neurons deficient for munc18-1
}

\author{
Joost H. Heeroma, ${ }^{1,2, \star}$ Martijn Roelandse, ${ }^{2,3, \star}$ Keimpe Wierda, ${ }^{2}$ Karlijn I. van Aerde, ${ }^{2}$ Ruud F. G. Toonen, ${ }^{1,2}$ \\ Robert A. Hensbroek, ${ }^{4}$ Arjen Brussaard, ${ }^{5}$ Andrew Matus ${ }^{3}$ and Matthijs Verhage ${ }^{1,2}$ \\ ${ }^{1}$ Department of Molecular Neuroscience, Rudolf Magnus Institute, University of Utrecht Medical Center, Utrecht, the Netherlands \\ ${ }^{2}$ Department of Functional Genomics, Center for Neurogenomics and Cognitive Research (CNCR), Vrije Universiteit Amsterdam \\ (VUA) and VU medical centre (VUmc), Amsterdam, the Netherlands \\ ${ }^{3}$ Friedrich Miescher Institute, PO Box 2543, 4002 Basel, Switzerland \\ ${ }^{4}$ Department of Neuroscience, Erasmus University, Rotterdam, the Netherlands \\ ${ }^{5}$ Department of Neurophysiology, VUA, CNCR, Amsterdam, the Netherlands
}

Keywords: apoptosis, loxP, mouse, regulated secretion, trophic support

\begin{abstract}
The stability of neuronal networks is thought to depend on synaptic transmission which provides activity-dependent maintenance signals for both synapses and neurons. Here, we tested the relationship between presynaptic secretion and neuronal maintenance using munc18-1-null mutant mice as a model. These mutants have a specific defect in secretion from synaptic and large dense-cored vesicles [Verhage et al. (2000), Science, 287, 864-869; Voets et al. (2001), Neuron, 31, 581-591]. Neuronal networks in these mutants develop normally up to synapse formation but eventually degenerate. The proposed relationship between secretion and neuronal maintenance was tested in low-density and organotypic cultures and, in vivo, by conditional cell-specific inactivation of the munc18-1 gene. Dissociated munc18-1-deficient neurons died within 4 days in vitro (DIV). Application of trophic factors, insulin or BDNF delayed degeneration up to 7 DIV. In organotypic cultures, munc18-1-deficient neurons survived until 9 DIV. On glial feeders, these neurons survived up to 10 DIV and 14 DIV when insulin was applied. Co-culturing dissociated mutant neurons with wild-type neurons did not prolong survival beyond 4 DIV, but coculturing mutant slices with wild-type slices prolonged survival up to 19 DIV. Cell-specific deletion of munc18-1 expression in cerebellar Purkinje cells in vivo resulted in the specific loss of these neurons without affecting connected or surrounding neurons. Together, these data allow three conclusions. First, the lack of synaptic activity cannot explain the degeneration in munc18-1-null mutants. Second, trophic support delays but cannot prevent degeneration. Third, a cellintrinsic yet unknown function of munc18-1 is essential for prolonged survival.
\end{abstract}

\section{Introduction}

During brain development a surplus of neurons and synapses is formed, after which many neurons and synapses are eliminated. In various model systems, synaptic activity is a major determinant in synapse elimination (for review see Lichtman \& Colman, 2000; Katz \& Crowley, 2002). For instance, blocking neuromuscular transmission during the critical period prevents neuromuscular synapse elimination (Duxson, 1982). Furthermore, blocking synaptic transmission in a subset of motor neurons selectively eliminates the inactive synapses (Buffelli et al., 2003). Similarly, inhibiting synaptic activity in the visual cortex prevents synapse elimination, while selectively suppressing activity in a subset of synapses (for instance by closing one eye) results in the elimination of the less active synapses (for review see Katz \& Crowley, 2002). For neuronal survival, similar rules apply because blocking neuromuscular transmission, either genetically or pharmacologically, also prevents naturally occurring motor neuronal elimination (Houenou et al., 1990; Banks et al., 2001). Activity-based

Correspondence: M. Verhage, ${ }^{2}$ Department of Functional Genomics, as above.

E-mail: matthijs@cncr.vu.nl

*J. H. Heeroma and M. Roelandse contributed equally to this paper.

Received 23 December 2003, revised 16 April 2004, accepted 17 May 2004 competition for target-derived trophic substances has been proposed to underlie these elimination processes (Katz \& Shatz, 1996; Sanes \& Lichtman, 1999); however, the exact mechanism underlying synaptic and neuronal elimination still remains unknown.

We have previously generated munc18-1-null mutant mice, which completely lack spontaneous and evoked neurotransmitter secretion and die at birth (Verhage et al., 2000). Brain development in munc181-null mutant mice is normal up to the point of synapse formation, after which widespread neurodegeneration occurs in the same order as initial development, i.e. early-maturing brain regions degenerate first. Degenerating cells in the mutant brain have electron-dense nuclei and cytoplasm, condensed chromatin and are terminal dUTP nick end labelling (TUNEL)-positive, suggesting that munc18-1-deficient neurons die through apoptosis (Verhage et al., 2000). We proposed that this degeneration is due to the absence of synaptic activity and, in line with this, we found that sensory dorsal root ganglia, which are unique in not depending on synapses for their activity, are spared from degeneration (Heeroma et al., 2003). Secretion from large dense-cored vesicles (LDCV) is also severely compromised in the munc18-1-null mutant (Voets et al., 2001; N. Korteweg and M. Verhage, unpublished observations). As LDCV secretion is probably the source of many neurotrophic substances (Berg et al., 2000; Wang et al., 2003), 
reduced LDCV secretion may also contribute to the degeneration of neuronal networks.

We exploited the munc18-1-null mutant as a model to characterize the role of synaptic input and trophic support for the survival of neurons and neuronal networks in vitro and in vivo. We used neocortical and hippocampal neurons, of munc18-1-null mutant and control embryos, in low-density, micro-island and organotypic cultures, subjected these neurons to different conditions of activation and trophic support and analysed the effects on survival. Moreover, we also generated a conditional null allelle of the munc18-1 gene in order to perform cell-specific deletion of munc18-1 expression in vivo and analyse the fate of munc18-1-deficient neurons in an otherwise normal brain. We used L7-Cre mice (Barski et al., 2000) to specifically delete expression in the Purkinje cells of the cerebellum. We found that coculturing with control neurons delayed degeneration of munc18-1null mutant neurons in organotypic, but not low density or microisland cultures. Providing trophic support with insulin, BDNF, glial feeder cells or organotypic cultures delayed but could not prevent degeneration of mutant neurons. Finally, cell-specific deletion of munc18-1, in vivo, resulted in specific degeneration of munc18-1deficient neurons, suggesting that munc18-1-deficient neurons do not degenerate due to a lack of synaptic input or trophic support, but because munc18-1 is essential for long-term neuronal survival, regardless of its role in regulated secretion.

\section{Materials and methods}

\section{Laboratory animals}

Munc18-1-deficient mice have been described previously (Verhage et al., 2000). For various experiments, munc18-1-deficient mice were crossed with either mice expressing soluble green fluorescent protein (gfp) (a kind gift of Dr A. Nagy) or mice expressing a green fluorescent protein (GFP)-based neuronal surface marker (gfptkras; Roelandse et al., 2003). Pregnant females were killed by cervical dislocation. Mouse embryos were obtained by caesarian section of pregnant females from timed heterozygous matings. Purkinje cellspecific knockout mice were created using Cre-loxP-mediated recombination. L7-cre transgenic mice (Barski et al., 2000) were crossed with loxp-munc18-1 mutants. Loxp-munc18-1 mutants were created by insertion of loxP sites flanking exon 2 of the munc18-1 gene by homologous recombination in embryonic stem cells. The mouse lines and crosses that were used in each experiment are listed in Table 1. Animals were housed and bred in accordance with the European Communities Council Directive of 24 November 1986 (86/609/EEC). All animal experiments were approved of by the Dutch Committee for Experiments on Animals.

\section{Cortical cultures}

Cortices were dissected from embryonic day 18 (E18) mice and collected in Hanks balanced salts solution (HBSS; Sigma), buffered with $7 \mathrm{~mm}$ HEPES. After removal of the meninges, the cortices were minced and incubated for $20 \mathrm{~min}$ in trypsinated HBSS at $37^{\circ} \mathrm{C}$. After washing, neurons were triturated with fire-polished Pasteur pipettes, counted with a haemacytometer and plated in Neurobasal medium (Invitrogen) supplemented with 2\% B-27 (Invitrogen), 1.8\% HEPES, $1 \%$ glutamax (Invitrogen), $1 \%$ Pen/Strep (Invitrogen) and $0.2 \%$ $14.3 \mathrm{~mm} \beta$-mercapto-ethanol. Low-density cultures were plated on poly L-lysin-coated glass coverslips at $25,000 / \mathrm{cm}^{2}$. For island cultures, neurons were plated at $6,000 / \mathrm{cm}^{2}$ on islands of rat glia. Glial islands were obtained by spraying a $0.25-\mathrm{mg} / \mathrm{mL}$ rat tail collagen solution (BD Biosciences, Bedford, USA) on glass coverslips. After drying and UV sterilization, glial cells were plated at $600 / \mathrm{cm}^{2}$. In some experiments, $100 \mathrm{~nm}$ insulin (Sigma) or $50 \mathrm{nM}$ BDNF (Sigma) was added to prolong the lifespan of munc18-1deficient neurons. Half of the medium was replaced with fresh medium every week.

\section{Organotypic cultures}

Organotypic slice cultures from E18 hippocampi were prepared as follows. Mouse embryos were obtained by caesarean section of pregnant females from timed heterozygous mating. GFP-expressing animals were identified by direct inspection using a Leica MZ12 dissection microscope fitted with fluorescence optics. Brains were dissected in ice-cold dissection Gey's balanced salt solution (dGBSS, consisting of GBSS (Invitrogen) with $0.65 \mathrm{~g}$ glucose and $200 \mu \mathrm{M}$ kynurenate, $\mathrm{pH}$ 7.4) and cut into 400- $\mu \mathrm{m}$-thick slices using a McIlwain tissue chopper (Mickle Engineering, Gomshall, UK). After separating individual slices, the hippocampal region was dissected out and separated. These hippocampal slices were kept at $4{ }^{\circ} \mathrm{C}$ in dGBSS for $45 \mathrm{~min}$ to recuperate. All subsequent procedures were identical to those described for organotypic slice cultures from postnatal day $(\mathrm{P}) 8$ mice (Gahwiler et al., 1998). For confocal imaging, slices were mounted in purpose-built chambers (Life Imaging Services, Olten, Switzerland) and observed under continuous superfusion with artificial cerebrospinal fluid (ACSF; in mM: $\mathrm{NaCl}, 124 ; \mathrm{KCl}, 2.5 ; \mathrm{MgSO}_{4}, 2.0$; $\mathrm{KH}_{2} \mathrm{PO}_{4}, 1.25 ; \mathrm{NaHCO}_{3}, 26$; glucose, 10 ; sucrose, 4 ; and $\mathrm{CaCl}_{2}, 2.5$ ) saturated with $95 \% \quad \mathrm{O}_{2}: 5 \% \quad \mathrm{CO}_{2}$ using a Yokogawa microlens Nipkow confocal system (Perkin Elmer, Life Science Resources, Cambridge, UK). Images were acquired using a cooled CCD camera (PCO Computer Optics GmbH, Kelheim, Germany) and analysed with MetaMorph software (Universal Imaging Corp., West Chester PA, USA).

TABLE 1. Mouse lines and crosses that were used in this study

\begin{tabular}{|c|c|c|c|}
\hline Crosses & Experimental group & Control group & Experiment \\
\hline Munc $18-1^{+/-} \times \operatorname{munc} 18-1^{+/-}$ & Munc18-1 $1^{-/-}$ & Munc18-1 $1^{+/-}$, munc18-1 $1^{+/+}$ & $\begin{array}{l}\text { Micro-island culture, } \\
\text { low density (coculture) }\end{array}$ \\
\hline Munc18-1 ${ }^{+/-} ;$gfp $\times$munc18-1 $1^{+/-} ;$gfp & Munc18-1 $1^{-/-}$; gfp & Munc18-1 ${ }^{+/-} ;$gfp, munc18-1 ${ }^{+/+}$gfp & $\begin{array}{l}\text { Micro-island culture, } \\
\text { low density (coculture) }\end{array}$ \\
\hline Munc18-1 ${ }^{+/-}$; gfptkras $\times$munc18-1 ${ }^{+/-}$; gfptkras & Munc18-1 $1^{-/}$; gfptkras & Munc18-1 ${ }^{+/-}$; gfptkras, munc18-1 ${ }^{+/+}$gfptkras & Organotypic culture \\
\hline Loxp-munc18-1 $1^{+/+} \times$munc18-1 $1^{+/-} ; 17 \mathrm{cre}^{+/+}$ & Loxp-munc $18-1^{+/+} 17 \mathrm{cre}^{+/-}$ & Loxp-munc $18-1^{+/-} ; 17 \mathrm{cre}^{+/-}$ & $\begin{array}{l}\text { Conditional cerebellar } \\
\text { Purkinje cell-specific } \\
\text { loxp-munc18-1 knockout }\end{array}$ \\
\hline
\end{tabular}




\section{Electrophysiological recordings}

Whole-cell current-clamp recordings were performed on cultured neurons at 8 and 9 days in vitro (DIV). The patch pipette contained the following solution (in $\mathrm{mM}$ ): $\mathrm{K}^{+}$-gluconic acid, $125 ; \mathrm{NaCl}, 10 ; \mathrm{MgCl}_{2}$, 4.6; K2-ATP, 4; creatine phosphate, 15; and EGTA, 1; with $20 \mathrm{U} / \mathrm{mL}$ phospocreatine kinase $(\mathrm{pH} 7.30)$. External medium contained (in $\mathrm{mM}$ ): $\mathrm{NaCl}, 140 ; \mathrm{KCl}, 2.4 ; \mathrm{CaCl}_{2}, 4 ; \mathrm{MgCl}_{2}, 4 ; \mathrm{HEPES}, 10$; and glucose, 10; ( $\mathrm{pH} 7.30)$. Glutamate $(1 \mathrm{mM})$ was added using an application pipette for the duration of $4 \mathrm{~s}$ (with a picospritzer). An Axopatch 200A was used for whole-cell recordings. Signals were acquired using Digidata $1322 \mathrm{~A}$ and Clampex 8.1. Clampfit 8.0 was used for offline analysis.

\section{Immunocytochemical procedures}

Dissociated cultures were fixed by adding $4 \%$ paraformaldehyde (PFA) to the medium in a $1: 1$ ratio. After 15 min the PFA-medium mixture was exchanged for 4\% PFA, for $15 \mathrm{~min}$. After washing with PBS the cells were permeated with $0.1 \%$ Triton $\mathrm{X}-100$ for $5 \mathrm{~min}$. After washing with PBS the cells were ready for processing or storage. Before staining the cells were incubated in $4 \%$ fetal calf serum for 20 min to block non-specific reactions. After washing with PBS the cells were incubated in a mixture of antibodies and $0.1 \%$ Triton X-100 for $1 \mathrm{~h}$ at room temperature or overnight at $4{ }^{\circ} \mathrm{C}$. The antibodies used were: mouse anti-MAP2 (1:200, Boehringer Mannheim), mouse anti-HPC1 (syntaxin; $1: 1000$; Sigma), rabbit anti-S100 $\beta$ (1:400; Dako, Glostrup, Denmark). After washing three times for 5 min with PBS, the cells were incubated for $1 \mathrm{~h}$ at room temperature in goat antimouse Alexa546 ( $1: 1000$; Molecular Probes, Oregon, USA). After washing in three times for $5 \mathrm{~min}$ in PBS the coverslips were mounted on microscope slides with Dabco-Mowiol and analysed with a Zeiss 510 Meta Confocal microscope.

Cultures slices were prepared by microwave-assisted fixation (Jensen \& Harris, 1989). Briefly, slices were transferred into prewarmed fixative [ $4 \%$ PFA, $0.5 \%$ glutaraldehyde and $2 \mathrm{mM} \mathrm{CaCl}_{2}$ in $0.1 \mathrm{M}$ cacodylate buffer (CCB), $\mathrm{pH} 7.3$ ] and irradiated at maximum power $(1000 \mathrm{~W})$ for $9 \mathrm{~s}$ in a Bio-Rad H2500 microwave processor. Post-irradiation temperature, measured by the built-in temperature probe, was $35-50{ }^{\circ} \mathrm{C}$. Slices were washed five times for $10 \mathrm{~min}$ in $0.1 \mathrm{M} \mathrm{CCB}$ and incubated overnight at room temperature in $0.3 \%$ Triton X-100, 5\% normal goat serum (NGS; Invitrogen) and 1\% bovine serum albumin (BSA; Sigma) in $0.1 \mathrm{M}$ CCB. Slices were then incubated overnight at room temperature in $0.1 \mathrm{M} \mathrm{CCB}$ with $0.3 \%$ Triton X-100, 5\% NGS, 1\% BSA, mouse anti-MAP2C (1: 5; Weisshaar et al., 1992) and rabbit anti-GFP (1 : 800; Novartis, Basel, Switzerland). After washing five times for $10 \mathrm{~min}$ each in $0.1 \mathrm{M} \mathrm{CCB}$ slices were incubated overnight at room temperature in $0.1 \mathrm{M} \mathrm{CCB}$ with $0.3 \%$ Triton X-100, 5\% NGS, 1\% BSA, goat antimouse Alexa546 ( $1: 200$; Molecular Probes) and goat antirabbit Alexa488 (1 : 200; Molecular Probes). After washing, slices were stored at $4{ }^{\circ} \mathrm{C}$ in $0.1 \mathrm{M} \mathrm{CCB}$ and mounted for imaging in purpose-built chambers, as described above.

L7-cre $\times$ loxp-munc18-1 mutant and wild-type mice were anaesthetized with i.p. Nembutal injection and transcardially perfused with $4 \%$ PFA. Histochemistry was performed by incubating cryosections ( $25 \mu \mathrm{m}$ thickness) for $3 \mathrm{~min}$ in $0.05 \%$ thionine. Sections were analysed using light microscope (DM-RB, Leica) equipped with a digital camera. Immunocytochemistry was performed on cryosections ( $25 \mu \mathrm{m}$ thickness), rinsed in $0.05 \mathrm{M}$ Tris ( $\mathrm{pH} 7.6)$ and preincubated in blocking buffer (5\% normal horse serum and $0.25 \%$ Triton X-100 in $0.5 \mathrm{M}$ Tris) for $60 \mathrm{~min}$. GAD antibody (sh-a-GAD, $1: 2000$, kind gift of Dr Oertel, Department of Neurology, Philipps University Marburg, Germany) and calbindin antibody (r-a-CaBp, 1:10000; Swant, Bellinzona, Switserland) were diluted in blocking buffer, and sections were incubated for $24 \mathrm{~h}$ at room temperature. After incubation, samples were rinsed in Tris, followed by $15 \mathrm{~min}$ incubation in $0.125 \%$ glutaraldehyde in $0.5 \mathrm{M}$ Tris. Incubation with the secondary antibodies Cy3 (d-a-sh, $1: 200)$ and Fitc (d-a-r, $1: 200$; both from Jackson Immuno Res. Laboratory Inc, West Grove, USA) was performed in blocking buffer for $2 \mathrm{~h}$ at room temperature. Fluorescence was documented using confocal imaging microscopy (LSM 510 inverted confocal microscope, argon-krypton laser; Zeiss).

\section{Results}

Munc18-1-deficient neurons in culture lacked neurotransmitter secretion but were otherwise biophysically normal

Munc18-1-deficient neurons in the neocortex and spinal cord lack neurotransmitter secretion at E15, 16 and 18 (Verhage et al., 2000). Here, we investigated whether this holds true for neurons in vitro cultured beyond E18 and whether the absence of munc18-1 affects other biophysical properties of cultured neurons. The resting membrane potential $\left(V_{\text {rest }}\right)$ is generally accepted as an informative parameter for the viability and health of (cultured) neurons (Pancrazio et al., 2001). The $V_{\text {rest }}$ of munc18-1-deficient neurons in autaptic island cultures of $8 \mathrm{DIV}$ was similar to control neurons $\left(V_{\text {rest,control }}=\right.$ $-52.0 \pm 2.0 \mathrm{mV}, n=5 ; V_{\text {rest,mutant }}=-51.1 \pm 5.4 \mathrm{mV}, n=5$; insets, Fig. 1A). Current injection into neurons (DIV 8) induced action potentials in both control and mutant neurons ( $n=5$, Fig. 1A). Current injection varied between recordings, because injection was manual and not standardized between recordings. This explains the different action potential frequency between the recordings of munc18-1-deficient neurons and control neurons. However, in whole-cell voltage-clamp recordings both spontaneous and evoked release were absent in mutant neurons (data not shown, $n=10$ ), whereas control neurons exhibited spontaneous events at $0.5-2 \mathrm{~Hz}$, with 10-200 pA amplitudes, and evoked responses of $0.1-2 \mathrm{nA}$ amplitudes. $\mathrm{Na}^{+}$and $\mathrm{K}^{+}$currents were similar in control and mutant neurons (Fig. 1B).

We have previously shown that munc18-1-deficient neurons express functional GABA and acetylcholine receptors (Verhage et al., 2000). As the majority of central synapses are driven by glutamate, we tested whether munc18-1-deficient neurons express functional glutamate receptors. Glutamate application $(1 \mathrm{~mm}, 4 \mathrm{~s})$ elicited both a fast [AMPA-receptor (-R) mediated] and a slow (NMDA-R mediated) response in control and mutant neurons (7-8 DIV) indicating that both types of glutamate receptors are present and functional in mutant neurons ( $n=9$ and 11, respectively; Fig. 1C). Thus, apart from the lack of synaptic vesicle secretion in munc18-1-deficient neurons, we did not detect additional biophysical differences between mutant and control neurons.

\section{Munc18-1 was essential for neuronal viability}

We analysed survival of munc18-1-null mutant neurons from neocortex and hippocampus in culture. Cortical neurons were plated at a density of $20000 / \mathrm{cm}^{2}$ (Fig. 2A and D). Trypan Blue staining indicated that the viability of mutant and control neurons after dissociation was similar (data not shown). As another measure for viability after dissociation, neuronal attachment to the substrate was analysed at 2, 6 and $24 \mathrm{~h}$ after plating. At all three time-points, $>95 \%$ 

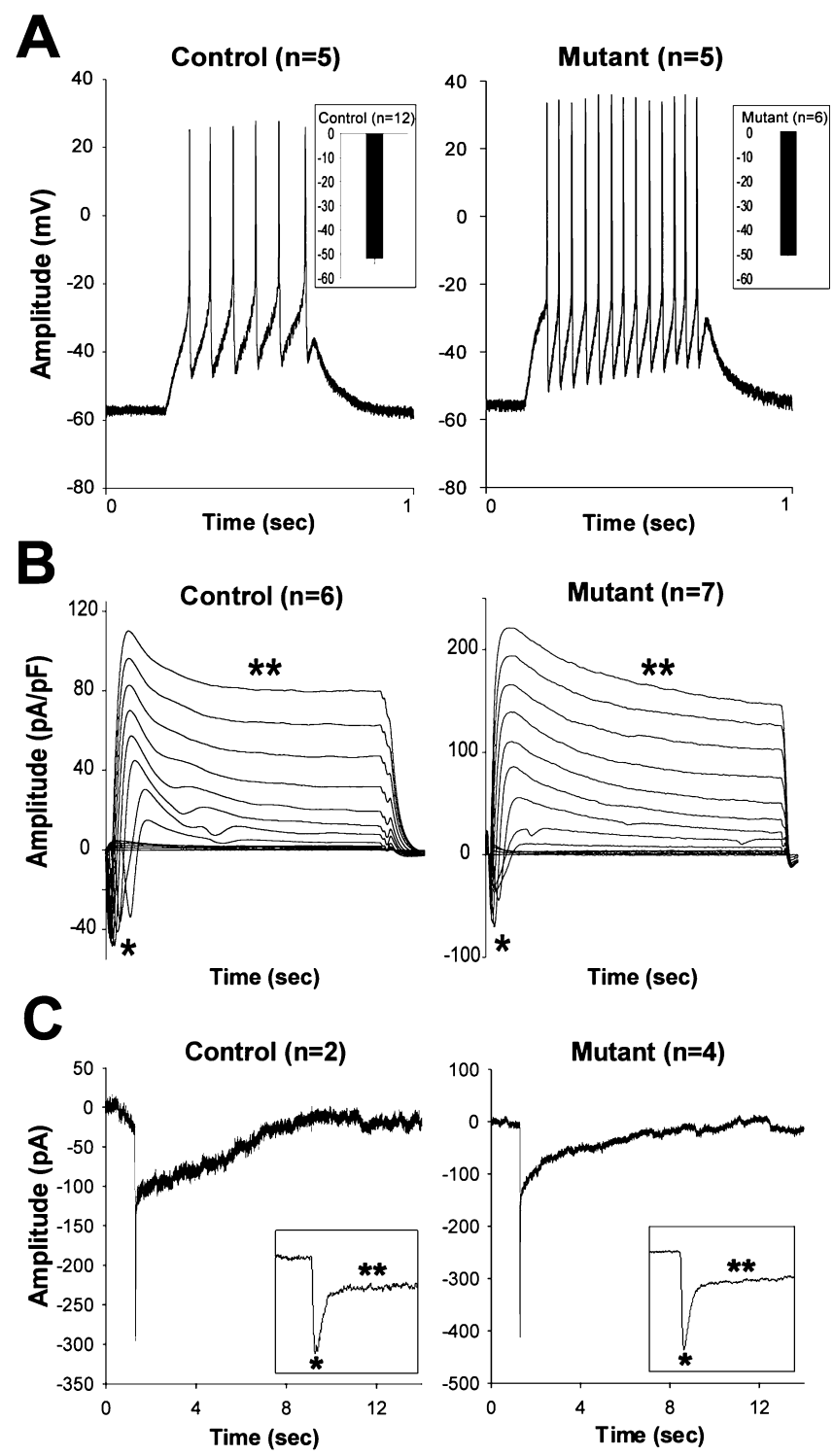

FIG. 1. Electrophysiological characterization of munc18-1-deficient neurons in culture. (A) Current injection into cultured neurons induced action potentials in both control and munc18-1-mutant neurons $(n=5)$. The amount of current injection was not monitored during the recordings. The difference in action potential frequency can thus be explained by the variable amount current injection between recordings. The $V_{\text {rest }}$ of autaptic islands of munc18-1deficient neurons is very similar to control autaptic neurons $(P=0.86$; see inset in panel A). (B) The $\mathrm{Na}^{+}$and $\mathrm{K}^{+}$channel expression was studied using repetitive block-pulse stimulation ( $200 \mathrm{~ms}$ block pulse; -70 to $+40 \mathrm{mV} ; 10-\mathrm{mV}$ increments). Both control $(n=6)$ and mutant $(n=7)$ neurons show $\mathrm{Na}^{+}$ currents $\left(*\right.$, tetrodotoxin-sensitive) and $\mathrm{K}^{+}$currents (**, compound current). (C) Example traces of glutamate application inducing inward current in both wild-type $(n=9)$ and mutant $(n=11)$ neurons $\left(V_{\mathrm{m}}=-70 \mathrm{mV}\right)$. Inset: First $6 \mathrm{~s}$ of amplification. A fast AMPA component $(*)$ and a slow NMDA component $(* *)$ were observed in recordings from both control and mutant neurons.

of both mutant and control neurons were attached (data not shown), suggesting equal initial viability in both groups.

After $3 \mathrm{DIV}$, the number of control and mutant neurons, identified by microtubule-associated protein 2 (MAP2) staining, was counted in 24 randomly chosen fields of $0.137 \mathrm{~mm}^{2}$ (Fig. 2B and E). For control neurons the average count $( \pm \mathrm{SD})$ was $21.5 \pm 6.7$, compared to
$22.2 \pm 5.4$ per field for mutant neurons. This corresponds to a density of $\approx 16000 / \mathrm{cm}^{2}$, suggesting a $20 \%$ loss between 0 and 3 DIV for both groups.

After 7 DIV, neurons were counted in 48 randomly chosen fields of $0.137 \mathrm{~mm}^{2}$ (Fig. 2C and F). Control culture average density was $15.4 \pm 4.9$ neurons whereas in mutant cultures neurons were rarely encountered (average $0.7 \pm 0.7$ neurons per field). Thus, while 7-DIV control neurons were still present at a density of $11200 / \mathrm{cm}^{2}$, the majority of mutant neurons had died by 7 DIV. This indicates that munc18-1-deficient neurons, obtained from E18 neocortex, are as viable as control neurons during the first 3 DIV. However the massive loss of munc18-1-deficient neurons between 3 and 7 DIV suggests a critical role for munc18-1-dependent processes in neuronal viability in later stages.

\section{Co-culturing munc18-1-deficient neurons with wild-type neurons did not improve neuronal viability}

The degeneration of munc18-1-deficient neurons may be due to a lack of synaptic input and may thus be prevented by culturing mutant and wild-type neurons together in a low-density culture so that mutant neurons receive synaptic input from wild-type neurons. To identify the different neuronal populations, the munc18-1-null mutation was crossed into transgenic mice expressing $g f p$ under the control of the CMV promoter (see Table 1). Cocultures were prepared using muncl8-1-deficient $g f p$-expressing neurons with nonfluorescent control neurons and, vice versa, of $g f p$-expressing control neurons together with nonfluorescent muncl8-1-deficient neurons.

At 3 DIV, the development of munc18-1-deficient neurons was indistinguishable from $g f p$-expressing wild-type neurons. Neurons of both genotype had formed mixed neuronal networks with dense reciprocal innervation (Fig. 3A-I). At 4 DIV, in cocultures of munc181-deficient $g f p$-expressing neurons with nonfluorescent control neurons, few mutant neurons, identified by MAP2 staining, remained in coculture (Fig. 3J-L). At $5 \mathrm{DIV}, \approx 0.001 \%$ of mutant neurons remained in coculture, similar to mutant neurons in monoculture. At 14 DIV, some GFP-positive cells were still in culture, but these cells lacked MAP2 staining (Fig. 3M-O) and were probably glial cells (discussed below). Therefore our data suggests that culturing munc181-deficient neurons with wild-type neurons has no noticeable effect on neuronal viability.

\section{Trophic factors delayed the degeneration of munc18-1-deficient neurons}

Munc18-1-deficient neurons may degenerate due to a lack of trophic support. Addition of trophic and/or neuromodulatory substances to the culturing medium might therefore prevent this degeneration. Brain-derived neurotrophic factor (BDNF) and insulin are known to have a trophic and survival-promoting effect on neurons (Lindholm et al., 1996; Yamada et al., 2001). Addition of $100 \mathrm{nM}$ of insulin to the culturing medium prevented the massive loss of munc18-1-deficient neurons at $4 \mathrm{DIV}$ and allowed their survival up to $7 \mathrm{DIV}$ (data not shown). However, the number of munc18-1-deficient neurons that reached 7 DIV was lower $(\approx 1 \%)$ than in control cultures $(\approx 50 \%)$ and, between 7 and $11 \mathrm{DIV}$, the remaining neurons degenerated. Addition of BDNF to the culturing medium had a similar effect on mutant neuron viability (data not shown). Thus, application of insulin or BDNF delays but does not prevent degeneration of munc18-1deficient neurons. 

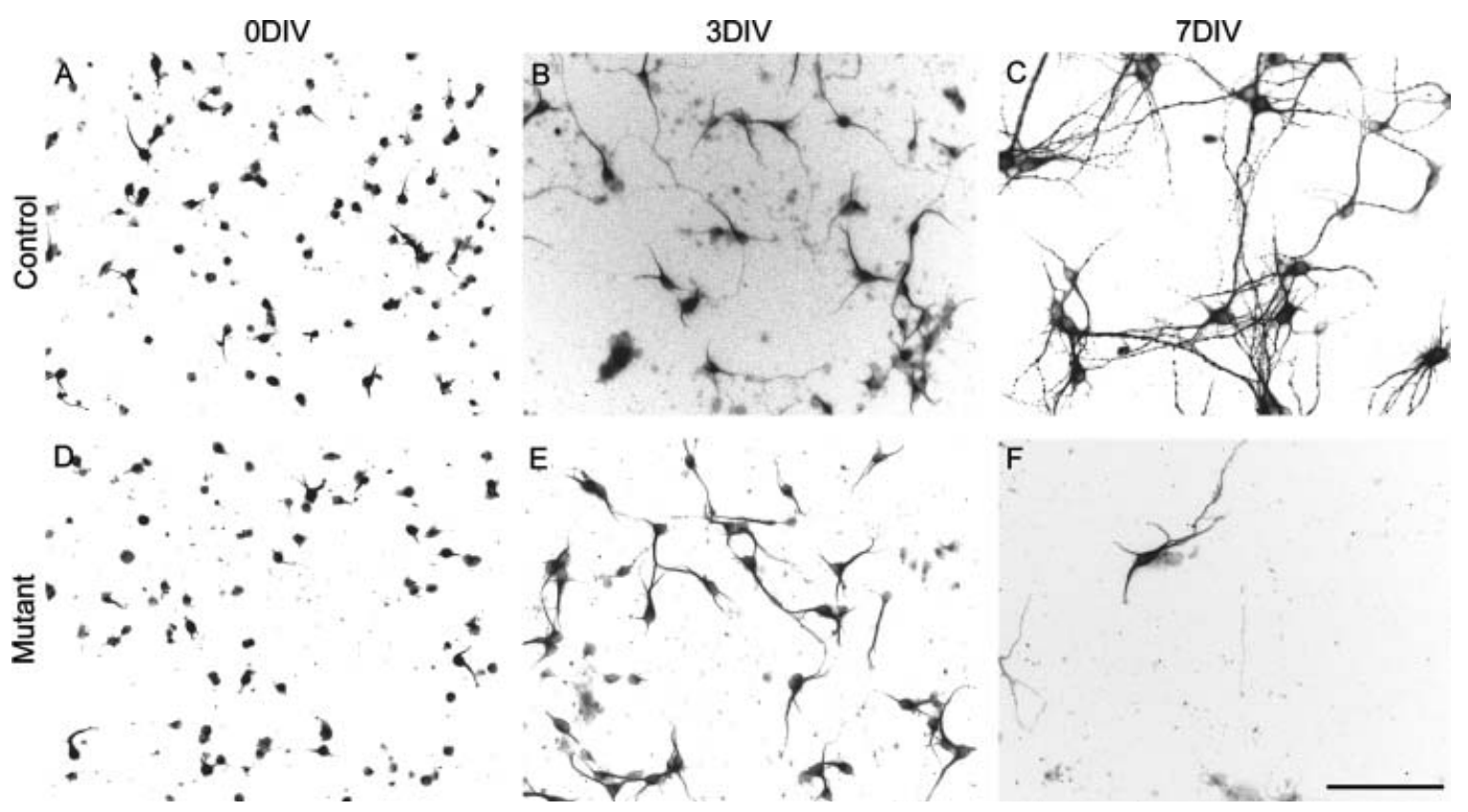

FIG. 2. Survival in vitro of munc18-1-null mutant neurons and their controls. (A-C) Control and (D-F) mutant neurons, identified by MAP2 staining, were plated at equal densities. At 3 DIV, control (B) and mutant (E) neurons were still in culture at equal densities. At 7 DIV, only a fraction of mutant neurons (F) was left in culture compared to the control situation (C). Scale bar, $50 \mu \mathrm{m}$.

\section{Culturing on glial cells delayed the degeneration of munc18-1-deficient neurons}

Most neuronal support in the brain is provided by glial cells (Barres, 1991). Therefore, glial support might compensate for the loss of munc18-1. To test this hypothesis, control and munc18-1-deficient neurons were cultured on a glial feeder layer. At 7 DIV, the number of munc18-1-deficient neurons in culture (Fig. 4B) was similar to that in control cultures (Fig. 4A) indicating that glial support indeed had a positive effect on the viability of munc18-1-deficient neurons. After 10 DIV on a glial feeder layer, $\approx 1 \%$ of munc18-1-deficient neurons were still in culture (Fig. 4C). Similar to the situation at 7 DIV, these neurons appeared morphologically underdeveloped and none survived past 10 DIV. Interestingly, when insulin was added to munc18-1-null mutant neurons cultured on glia, neurite branching and outgrowth and neuronal survival rate were still normal at 10 DIV (Fig. 4D). However, beyond $10 \mathrm{DIV}$, degeneration still occurred and no mutant neuron reached 14 DIV. Together, these data suggest that glial cells and insulin have a synergistic effect in promoting the viability of munc181 -deficient neurons. In addition, insulin aids munc18-1-deficient neurons in obtaining and maintaining normal neuronal morphology. Nevertheless, glial cells and insulin, both separate and in combination, failed to prevent eventual degeneration of mutant neurons.

\section{Organotypic culture with wild-type slices delayed the degeneration of munc18-1-deficient slices}

As trophic substances and glial cells worked synergistically in delaying degeneration of munc18-1-deficient neurons, embedding of these neurons in a more natural trophic environment might delay degeneration further. To test this, we used organotypic slice cultures of E18 hippocampus. The munc18-1-null allele was crossed into mice transgenically expressing $g f p$ linked to a plasma membrane targeting sequence (gfptkras; see Table 1), and therefore enabled detailed morphological analysis in living neurons (Roelandse et al., 2003).
Previous publications have shown that postnatal brain slices can be kept in vitro for months and that neuronal development in these slices closely resembles in vivo maturation (Gahwiler, 1984). Because munc18-1-deficient mice are postnatally moribund, E18 mice were used for generating the slice cultures. Cocultures of fluorescent and nonfluorescent wild-type slices are known to cross-innervate and to develop mature neuronal characteristics as dendritic spines and presynaptic varicosities (M. Roelandse and A. Matus, unpublished observations). Such a culture at 32 DIV is shown in Fig. 5A (middle panel); both hippocampi were equal in size and retained morphological features characteristic for the mature hippocampus.

Cultures of single munc18-1-deficient slices expressing gfptkras rapidly degraded during the first week (Fig. 5B, middle panel). At 9 DIV, some MAP2-positive neurons were still present (Fig. 5B, right panel). However, at later stages all neurons had degenerated, suggesting that organotypic embedding, in itself, is not more successful in preventing degeneration of munc18-1-deficient neurons than combined glial and trophic support in island monocultures.

Low-density cocultures of munc18-1-deficient and control neurons did not delay the degeneration of mutant neurons. Interestingly, coculturing munc18-1-deficient slices, expressing gfptkras, with nonfluorescent control slices did delay the degradation of the fluorescently labelled munc18-1-deficient slice (compare Fig. 5B and $\mathrm{C}$, middle panels). At 9 DIV in coculture, there was no sign of neuronal degeneration in the munc18-1-deficient slice (Fig. 5C, right panel) whereas, in the single-mutant slice, neurons were virtually absent at the same stage (Fig. 5B, right panel). However, at 19 DIV the $g f p$ expressing munc18-1-deficient slice had degenerated, despite the presence of a control slice (Fig. 5D, middle panel). Still, some MAP2-positive neurons were present in the vicinity of the nonfluorescent wild-type culture (Fig. 5D, right panel). No mutant neurons were observed beyond 25 DIV. Quadracultures of three $g f p$-expressing wild-type slices and one munc18-1-deficient slice (Fig. 5E, middle panel) showed a dense invasion of $g f p$-expressing wild-type axons 

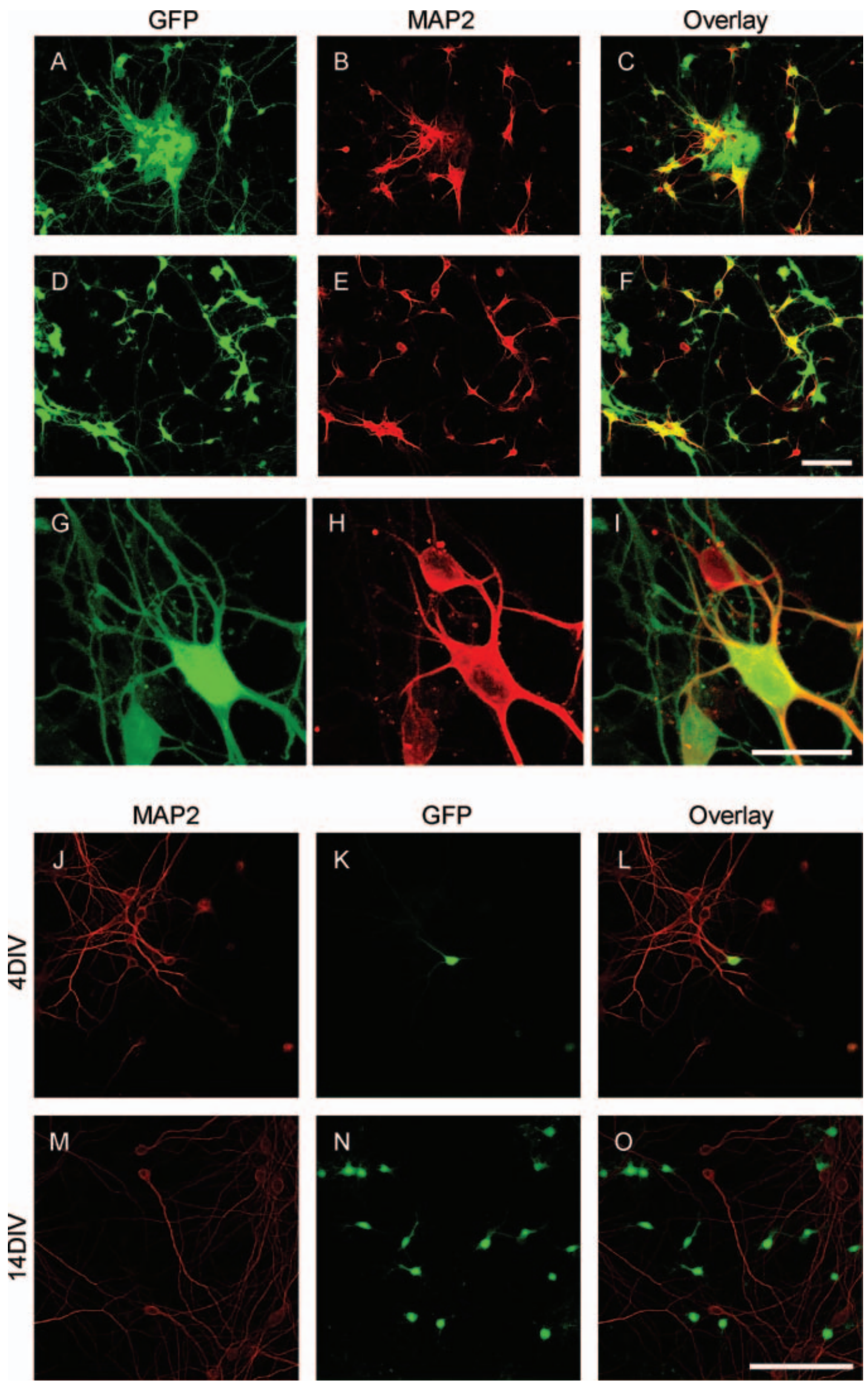

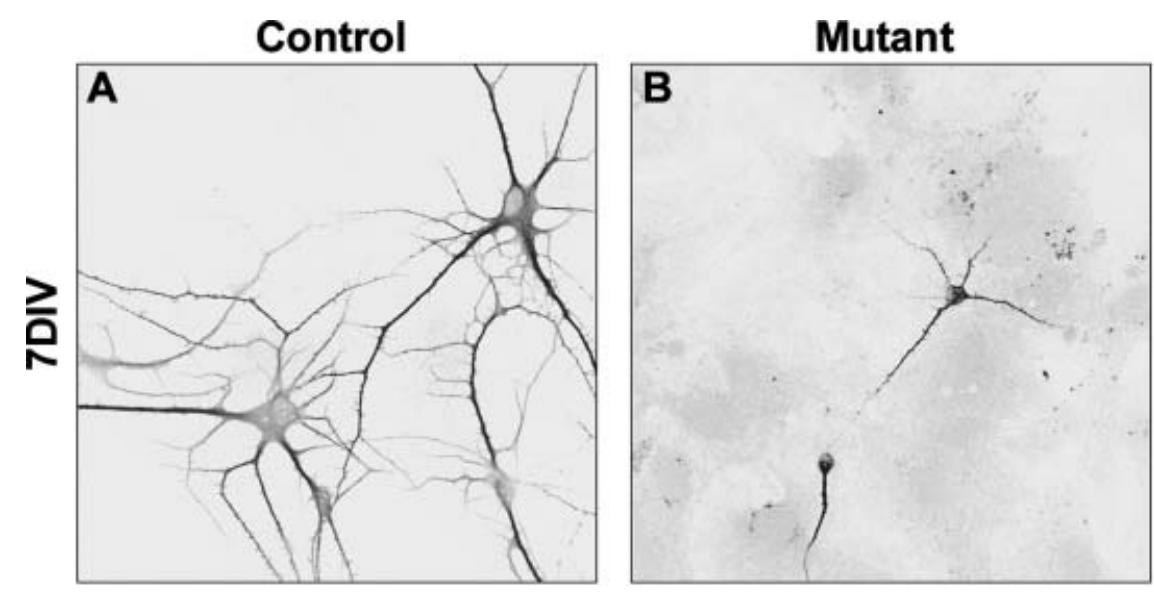

\section{Mutant with insulin}
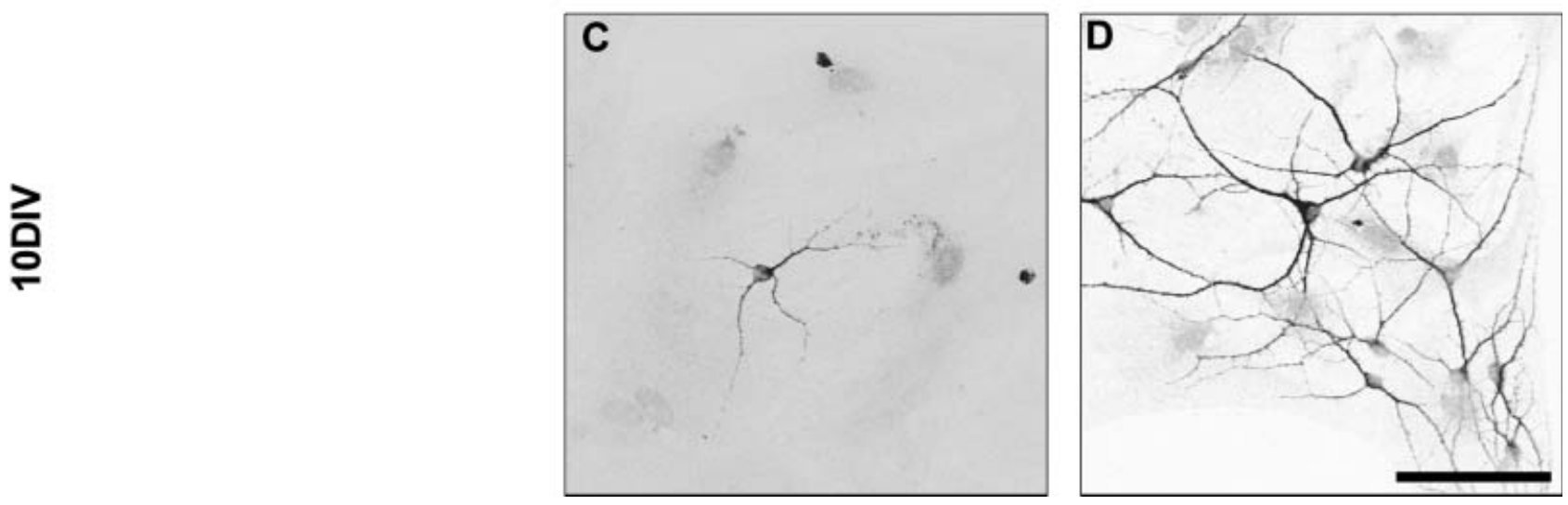

FIG. 4. The effect of glial support and insulin application on the degeneration of munc18-1-deficient neurons. Neurons were plated on glial feeder layers and stained for MAP2 for identification. (A and B) At 7 DIV, munc18-1-deficient neurons (B) were still present in numbers similar to control neurons (A). Mutant neurons had shorter neurites and fewer branching points. (C) At 10 DIV, some mutant neurons were still present but most had degenerated. (D) When insulin was added to these cultures, normal morphology was preserved and mutant neurons were viable for $\approx 13$ DIV. The scale bar, $50 \mu \mathrm{m}$.

surrounding a munc18-1-deficient neuron (identified by the red MAP2C counterstaining; Fig. 5E, right panel), suggesting that synaptic connections had been established. Together, this suggests that not organotypic slice culturing per se but coculturing with control slices prolongs the lifespan of the munc18-1-deficient neurons.

\section{Surviving munc18-1-deficient cells in culture were glial cells}

Eventually every neuron which lacked munc18-1 died prematurely. Some munc18-1-deficient GFP-positive and MAP2-negative cells survived to 14 DIV in mixed cultures (Fig. 3D-F). Figure 6B shows munc18-1-deficient cells of 21 DIV that were known to be mitotic and which were syntaxin-1-negative (see Fig. 6A and C). By visual inspection, two cell types could be distinguished among the remaining cells (Fig. 6D). One cell type had the morphology of type 2 astrocytes and indeed was S100ß-positive (Fig. 6E). The other cell type morphologically resembled oligodendrocytes. Hence, in contrast to neurons, glial cell viability seems not to be affected by the absence of munc18-1.

\section{Cell-specific deletion of munc18-1 in vivo causes specific loss of munc18-1-deficient neurons}

To analyse degeneration of munc18-1-deficient neurons beyond birth and without the complication of widespread apoptosis, we generated a mutant mouse in which munc18-1 expression could be conditionally deleted using the Cre-lox system. This munc18-1-lox mouse was crossed with a mouse transgenically expressing cre under control of the L7 promoter (see Table 1). Cre expression is specific for cerebellar Purkinje cells, starts at P 6 and is present in all Purkinje cells at postnatal week 3 (Barski et al., 2000). To allow depletion of remnant munc18-1 protein, the effect of munc18-1 deletion was analysed after 8 postnatal weeks. Animals homozygous for the munc18-1-lox allele and crossed to L7-Cre had developed severe ataxia by this time, suggesting a cerebellar defect. Nissl staining showed that overall cerebellar morphology of mutant mice (Fig. 7E) was indistinguishable from control mice (Fig. 7A), but closer examination showed that Purkinje cell bodies were absent in the mutant cerebellum (Fig. 7B and F). Staining for the Purkinje cell marker calbindin showed immunoreactivity in layer 4 of the cerebellum of control mice (Fig. 7C) but not

FIG. 3. (A-I) Co-culturing $g f p$-expressing wild-type neurons and munc18-1-deficient neurons resulted in the formation of neural networks of mixed origin. Left panels show only the $g f p$-expressing neurons, middle panels show MAP2 counterstaining to identify neurons and right panels show an overlay of both. (G-I) The higher magnifications clearly underline the fact that wild-type and muncl8-1-deficient neurons intermingle. Together they formed dense neuronal networks suggestive of wild-type afferent innervation onto munc18-deficient neurons. (J-O) Cocultures of $g f p$-expressing, munc18-1-deficient and wild-type neurons show a rapid decline in the numbers of munc18-1-deficient neurons. (J-L) At 4 DIV, very few MAP2-positive green cells were present in culture, suggesting few neurons had survived up to 4 DIV. (M-O) At 14 DIV, none of the gfp-expressing cells was MAP2-positive, indicating that all the munc18-1-deficient neurons had degenerated. Scale bar, $50 \mu \mathrm{m}(\mathrm{A}-\mathrm{F}), 25 \mu \mathrm{m}(\mathrm{G}-\mathrm{I}), 100 \mu \mathrm{m}(\mathrm{J}-\mathrm{O})$. 


\section{DF / GFP}

MAP2C / GFP
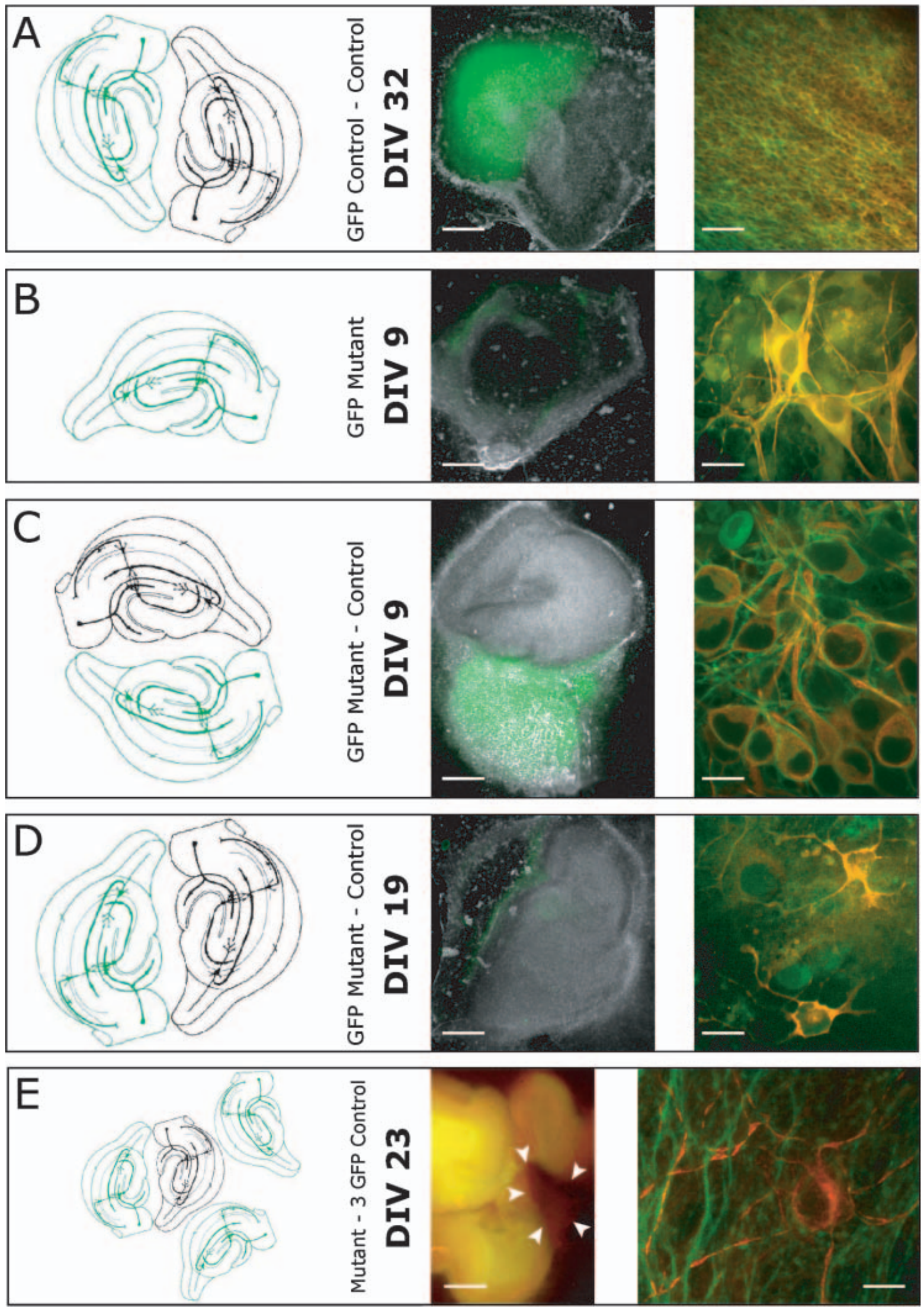
in the cerebellum of mutant mice (Fig. 7G). Finally, staining for glutamic acid decarboxylase (GAD), a general marker for inhibitory neurons, showed increased immunoreactivity in the Purkinje cell layer of control cerebelli (Fig. 7D), but not of mutant cerebelli (Fig. 7H). Apart from Purkinje cells, no obvious signs of degeneration were observed in the cerebellum. Together, these results suggest that cellspecific deletion of munc18-1 results in the specific loss of those neurons that lack munc18-1 without affecting connected or surrounding cells.

\section{Discussion}

In the present study, we tested the relationship between presynaptic secretion and neuronal maintenance in vitro and in vivo using neurons with munc18-1-null alleles as a model. We found that munc18-1deficient neurons have no synaptic secretion but have otherwise normal biophysical properties. These neurons degenerated in microisland, low density and organotypical cultures and in vivo. We found no evidence that synaptic activity delays or prevents degeneration. Trophic support, by exogenous application of trophic substances, glial support, or coculturing with wild-type organotypic slices, delayed but did not prevent degeneration. The effects of various treatments on survival of the mutant neurons are summarized in Fig. 8. Cell-specific deletion of munc18-1 expression in cerebellar Purkinje cells in vivo led to the specific loss of these neurons without affecting connected or surrounding cells.

\section{Munc18-1-deficient neurons are healthy at early developmental stages}

Degeneration of munc18-1-deficient neurons starts in the embryonic brain. Those brain areas that form synapses first also show the first signs of degeneration (Verhage et al., 2000). However, the viability of mutant neocortical neurons was unimpaired during plating and the first 3 DIV. Mutant neurons displayed normal resting membrane potentials and $\mathrm{K}^{+}$and $\mathrm{Na}^{+}$currents at $8 \mathrm{DIV}$ and expressed functional neurotransmitter receptors. Furthermore, mutant hippocampal neurons remained viable for up to 19 DIV when cocultured with control hippocampal slices. This suggests that mutant neurons were healthy at the time of plating and shortly thereafter and thus that munc18-1 expression is dispensable during early development and differentiation phases.

\section{The lack of synaptic activity is unlikely to explain the degeneration of munc18-1-deficient neurons}

We previously suggested that the degeneration in munc18-1-null mutant brain could be the consequence of the lack of synaptic activity in these mutants. This suggestion was based on a large body of (indirect) evidence that synaptic activity regulates synapse stability (see Verhage et al., 2000 and references herein) and, more specifically, the fact that munc18-1-deficient primary sensory neurons were selectively spared from degeneration (Heeroma et al., 2003). These neurons are different from the degenerating central neurons in the sense that they do not rely on synaptic transmission for their input, and are therefore expected to be the only neurons in the mutant that receive normal input. However, we show here that coculturing munc18-1-deficient neurons with control neurons did not prevent or even delay degeneration, although we cannot rule out that the synapses onto the munc18-1-deficient neurons may not have been functional. Still, specific deletion of munc18-1 expression in vivo in cerebellar Purkinje cells, i.e. without affecting the synaptic input onto these cells, led to a specific degeneration of the Purkinje cells. Hence, providing synaptic input is not sufficient to prevent degeneration of munc18-1-deficient neurons. Recently, a second genetic deletion has been described which also renders neurons completely silent: null mutation of munc13-1 and munc13-2 expression. In contrast to the munc18-1-null mutant neurons, these munc13 double-null mutant neurons survived in vivo and in vitro without signs of degeneration (Varoqueaux et al., 2002). Therefore, we conclude that receiving synaptic input per se is not important for neuronal survival and the lack of synaptic activity is unlikely to explain the degeneration of munc18-1-deficient neurons.

For motor neurons, there is clear evidence that synaptic activity at the terminals influences survival of the neurons (which have their soma in the spinal cord). Genetic (Banks et al., 2001) and pharmacological (Houenou et al., 1990) inhibition of transmission at the neuromuscular junction led to increased survival of motor neurons in the spinal cord. This suggests that neuronal output is an important factor in neuronal survival in this system, probably via a retrograde signal from the neuromuscular junction. In principle such a mechanism could explain the observed degeneration in munc18-1-null mutant neurons. However, it is unknown if such output dependency also applies to other systems than the neuromuscular junction and the lack of degeneration in munc13 double-null mutant neurons argues against this.

\section{Trophic support delays but does not prevent degeneration of munc18-1-deficient neurons}

In addition to the lack of synaptic vesicle secretion, munc18-1-null mutants also have severe impairments in the secretion from other secretory vesicles, for instance in chromaffin cells and the pituitary (Voets et al., 2001; N. Korteweg and M. Verhage, unpublished observations). As such vesicles are known to contain neurotrophic substances (Berg et al., 2000; Wang et al., 2003), degeneration of munc18-1-deficient neurons might be due to a lack of trophic support. The ability to properly secrete the content of such secretory vesicles could also explain the difference between the degenerating munc18-1deficient neurons and the viable munc13-1/2-deficient neurons. It is unknown whether munc13-1/2-deficient neurons are also impaired in other secretory routes than synaptic transmission. Indeed, treatment of munc18-1-deficient neurons with insulin or BDNF delayed degeneration. Culturing on glial cells allowed munc18-1-deficient neurons to

FIG. 5. Survival of hippocampal organotypic slice cultures of $g f p$-expressing, munc18-1-deficient neurons with and without cocultured wild-type slices. (A, middle panel) At $32 \mathrm{DIV}$, the gross morphology of cocultures of fluorescent and nonfluorescent (dark field) control slices was normal. (A, right panel) In a control hippocampal slice of 9 DIV, neurons were densely packed. In a munc18-1-deficient slice of 9 DIV (B, middle panel), few MAP2-positive neurons were present (B, right panel). (C, middle panel) Co-culturing munc18-1-deficient slices with control slices prevented massive degeneration before 9 DIV and (C, right panel) many MAP2-positive, munc18-1-deficient neurons were present. (D, middle panel) At 19 DIV in coculture, the munc18-1-deficient slice had deteriorated and (D, right panel) few munc18-1-deficient neurons were left. To maximize the innervation of wild-type axons we also made quadracultures of three $g f p$-expressing wild-type slices cocultured with one munc18-1-deficient slice. (E, middle panel) In these cultures, counterstained with MAP2C (red) at 23 DIV, still most of the munc18-1deficient slice had deteriorated as indicated by the arrowheads. However some neurons were nonetheless present and $g f p$-expressing wild-type axons had innervated the munc18-1-deficient tissue. Scale bar, $300 \mu \mathrm{m}$ (A-E, middle panels), $100 \mu \mathrm{m}$ (A, left panel) and $40 \mu \mathrm{m}$ (B-E, left panels). 

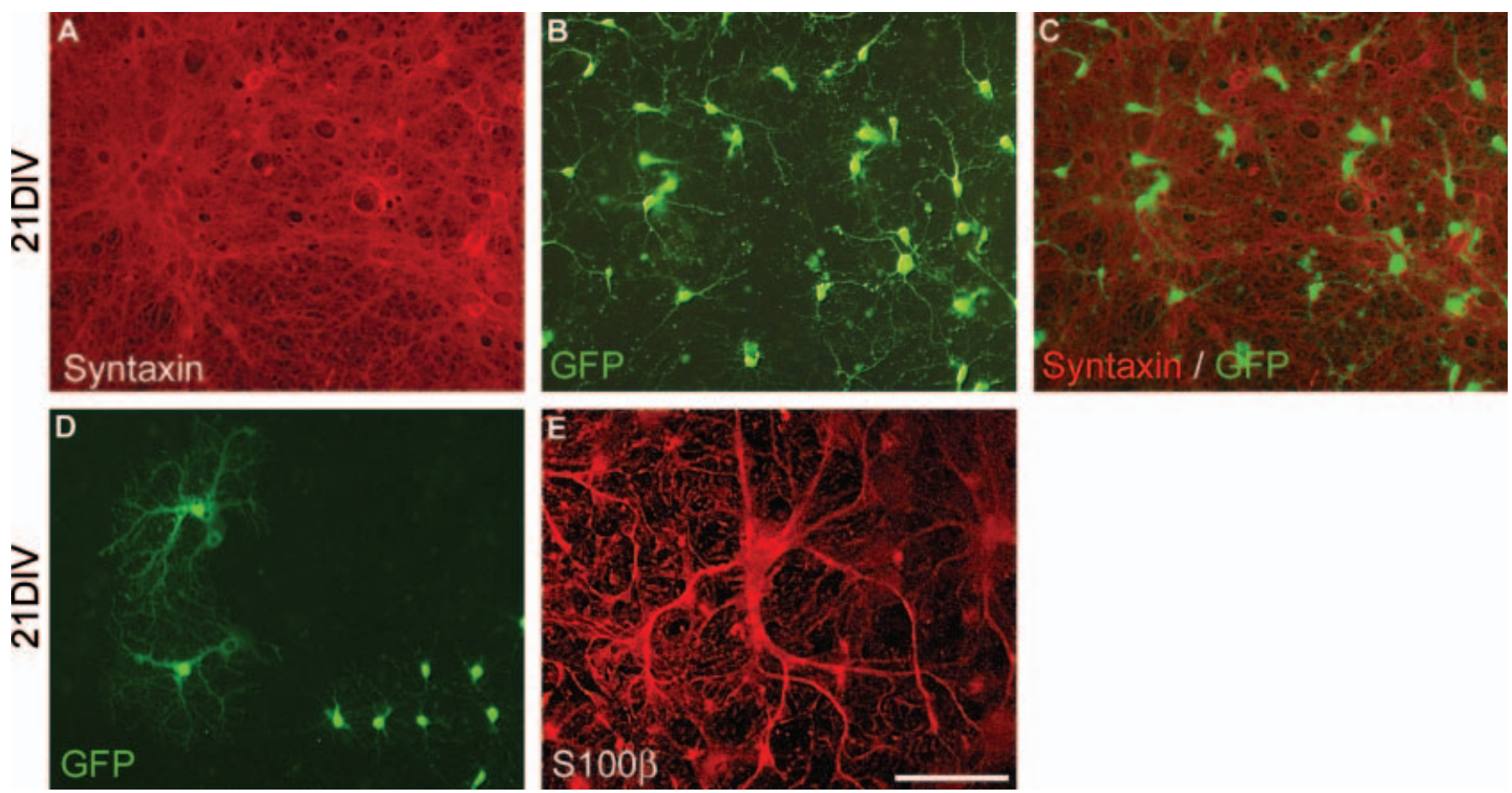

FIG. 6. Munc18-1-deficient glial cells remain in culture. When control and munc18-1-deficient $g f p$-expressing cortical cells were cocultured for 21 DIV, no munc18-1-deficient neurons were left in culture. (A) There was extensive syntaxin staining, showing the presence of a dense neuronal network. (B) There were a number of $g f p$-expressing cells indicating that some munc18-1-deficient cells were still present. (C) However, the gfp-expressing cells showed no structural overlap with the syntaxin staining and therefore were not syntaxin-positive, i.e. not of neuronal origin. When muncl8-1-deficient cortical cells were plated in monoculture, two cell types survived. Some of these remaining cells (D) had the morphological appearance of oligodendrocytes whereas (E) others were S100 $\beta$-positive and resembled type 2 astrocytes. Scale bar, $50 \mu \mathrm{m}$.

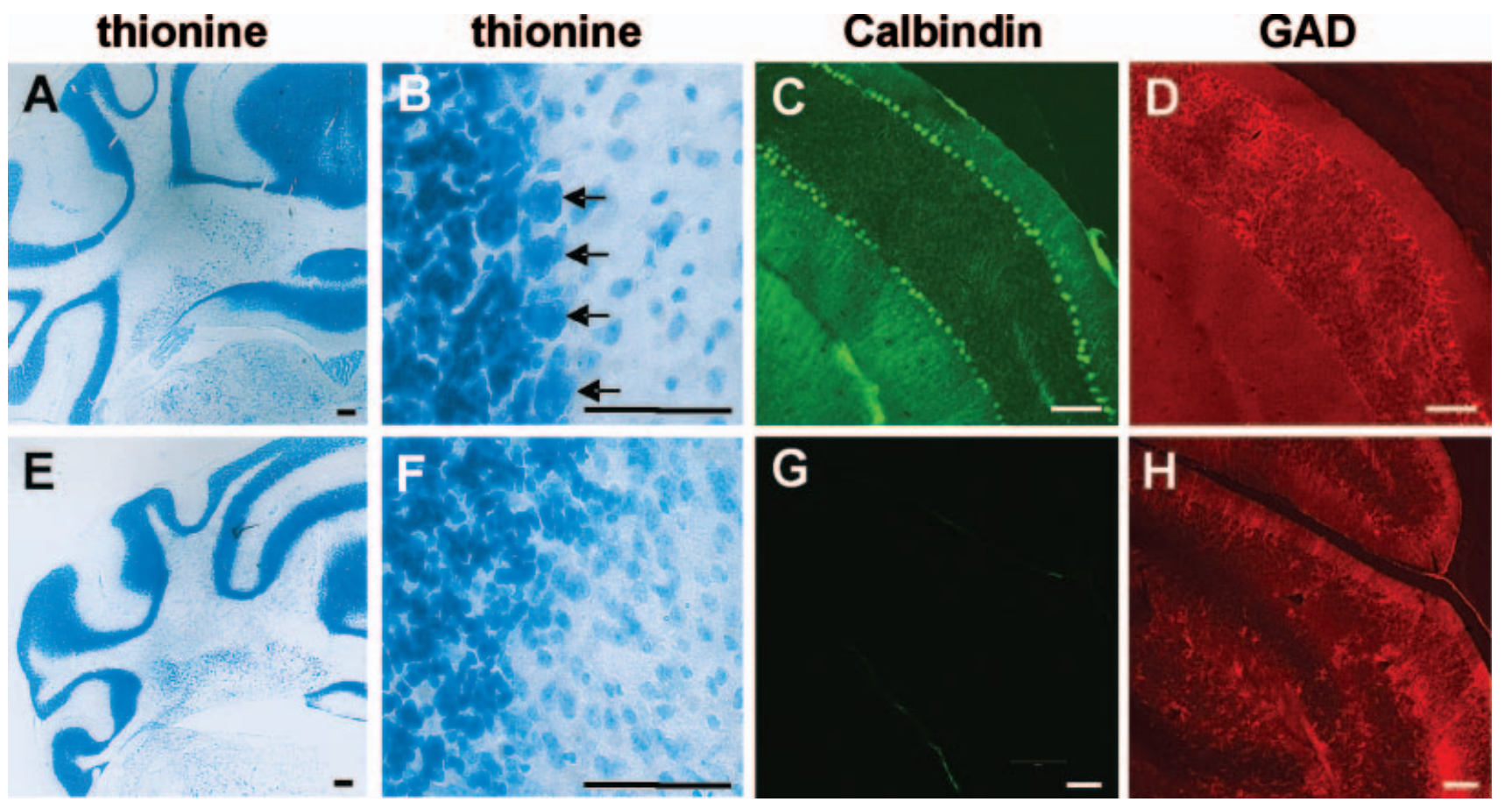

FIG. 7. Loss of munc18-1-deficient neurons in the cerebellum in vivo. (E-H) The Cre-LoxP system was used to specifically delete munc18-1 in postnatal cerebellar Purkinje cells. Nissl staining showed normal gross cerebellar anatomy in (E) adult mutant mice compared to (A) wild-types. Purkinje cells were present in (B, arrows) wild-types but (F) absent in mutants. Staining for the Purkinje cell marker calbindin showed (C) a normal pattern in wild-types, but (G) no positive cells in mutants. Staining for GAD showed (D) GABAergic interneurons and Purkinje cells in wild-types but (H) only interneurons in mutants. Scale bar, $100 \mu \mathrm{m}$. 


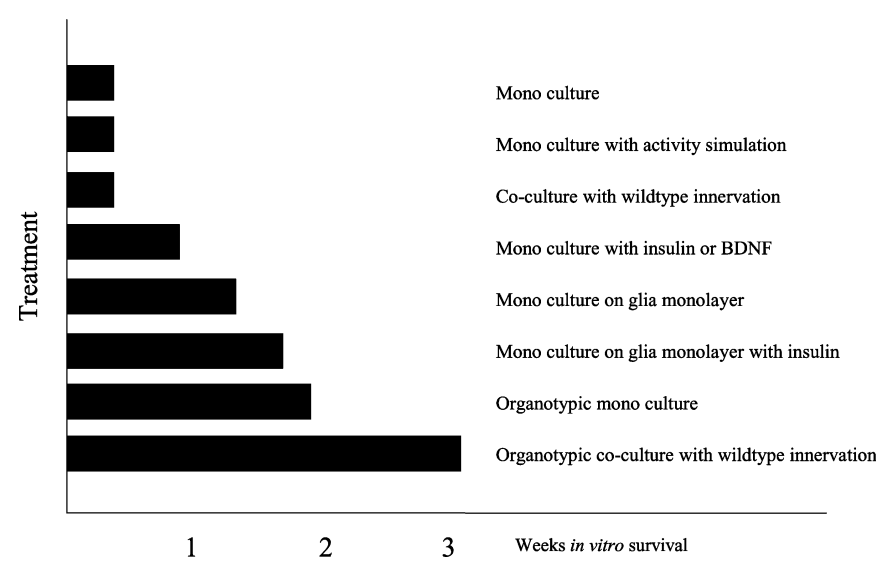

FIG. 8. Summary of the effects of various treatments on the survival of munc18-1-null mutant neurons.

survive up to 10 or even 14 DIV when insulin was added exogenously. In organotypic slices, munc18-1-deficient neurons were viable up to 19 DIV, provided they were cocultured with control slices. Still, eventually all mutant neurons degenerated. Also in vivo, cell-specific deletion of munc18-1 resulted in specific degeneration of cerebellar Purkinje cells. As the rest of the brain, including connecting and surrounding neurons, is unaffected it is unlikely that the trophic environment for these Purkinje cells was fundamentally different from control cells. Together, this indicates that neither trophic support nor the combination of trophic support and synaptic activity is sufficient to explain the degeneration of munc18-1-deficient neurons.

The observation that trophic support delayed degeneration of munc18-1-deficient neurons may be explained in several ways. The trophic actions of substances such as insulin and BDNF are multiple. Both substances reportedly stimulate neurite outgrowth, synapse formation, synapse activation and synaptic strength (Schulingkamp et al., 2000; Vicario-Abejon et al., 2002). Both substances are also known to exert survival-promoting effects, promoting survival under nonphysiological conditions such as serum deprivation in culture (Yamada et al., 2001; Hamabe et al., 2003). Therefore, the observed delay in munc18-1-deficient neuronal degeneration might be explained by suppression of apoptosis as well as promoting connectivity or both.

\section{An additional cellular function of munc18-1 is essential for prolonged neuronal survival}

Taken together, the currently available data suggest that absence of release from synaptic vesicles has by itself little effect on neuronal maintenance. The loss of secretion from other secretory vesicles is probably a negative factor, but still an insufficient explanation for the observed degeneration after deletion of munc18-1 expression. In this respect the munc18-1 gene is different from most other genes involved in secretion. Deletion of their expression dramatically reduces secretion and synaptic transmission in a number of cases (e.g. Harrison et al., 1994; Deitcher et al., 1998; Zhao \& Nonet, 2000; Schoch et al., 2001; Misgeld et al., 2002; Varoqueaux et al., 2002; Washbourne et al., 2002; Brandon et al., 2003) but, among these, very few show an equally strong phenotype as the munc18-1-null mutation, or have completely silent synapses: only the munc13-1/2 double-null mutation in mice and probably syntaxin mutations in Drosophila (Verhage et al., 2000; Saitoe et al., 2001; Featherstone et al., 2002; Varoqueaux et al., 2002). Massive neuronal degeneration is only reported in munc18-1-null mutant mice and syntaxin-null mutant flies (Schulze \& Bellen, 1996; Verhage et al., 2000). The most likely explanation for this aspect of the phenotype is that munc18-1 has another cell-intrinsic and essential function, distinct from its established role in secretion. One possibility is that munc18-1 is not only required to keep syntaxin-1 available for synaptic vesicle fusion, but also to prevent (other) neuronal syntaxins from promiscuous interactions in other cellular processes involving vesicular trafficking (Toonen \& Verhage, 2003). Second, munc18-1 might be involved in the recognition of potential synaptic partners through MINT, CASK and neurexin (Biederer \& Sudhof, 2000). Third, munc18-1 might be necessary for the proper targetting of ion channels and transporter proteins (Naren et al., 1997; Khan et al., 2001). Fourth, munc18-1 has recently been shown to bind to cytoskeletal proteins, suggesting a role for munc18-1 in cytoskeletal rearrangement (Bhaskar et al., 2004). Finally, munc18-1 might exert another, yet unknown, function which is indispensable for long-term neuronal survival. Irrespective of what the additional role of munc18 proves to be, the results reported here demonstrate that the molecular mechanisms underlying the survival and maintenance of central nervous system neurons is less activitydependent than those that have been inferred from studies of the neuromuscular junction and less neurotrophin-dependent than has previously been thought, and instead involve novel cell-intrinsic mechanisms.

\section{Acknowledgements}

We thank Danielle Dam, Désirée Schut, Joost Hoetjes, Tatjana Westphal and Robbert Zalm for breeding and genotyping mutant mice. We also thank $\mathrm{Dr}$ Barski for providing L7-Cre mice. Most authors were supported by research grants from the Dutch Organization of Scientific Research (NWO: ALW80526-251 to J.J.H., ZonMW-GpD970-10-036 to K.W. and K.I.v.A., GMW90342-023 to R.F.G.T., ZonMW-903-47-098 to R.A.H. and ZonMW-PIO900-01001 to M.V.) M.R. and A.M. were supported by the Novartis Research Foundation.

\section{Abbreviations}

BDNF, brain-derived neurotrophic factor; BSA, bovine serum albumin; CCB, cacodylate buffer; CMV, cytomegalovirus; DIV, days in vitro; E18, embryonic day 18; GAD, glutamic acid decarboxylase; GFP, green fluorescent protein; $g f p$, green fluorescent protein (gene); HBSS, Hanks's balanced salts solution; LDCV, large dense-cored vesicle; MAP2, microtubule-associated protein 2; NGS, normal goat serum; P, postnatal day; PFA, paraformaldehyde; -R, -receptor; TUNEL, terminal dUTP nick end labelling; $V_{\text {rest }}$, resting membrane potential.

\section{References}

Banks, G.B., Chau, T.N., Bartlett, S.E. \& Noakes, P.G. (2001) Promotion of motoneuron survival and branching in rapsyn-deficient mice. J. Comp. Neurol., 429, 156-165.

Barres, B.A. (1991) New roles for glia. J. Neurosci., 11, 3685-3694.

Barski, J.J., Dethleffsen, K. \& Meyer, M. (2000) Cre recombinase expression in cerebellar Purkinje cells. Genesis, 28, 93-98.

Berg, E.A., Johnson, R.J., Leeman, S.E., Boyd, N., Kimerer, L. \& Fine, R.E. (2000) Isolation and characterization of substance P-containing dense core vesicles from rabbit optic nerve and termini. J. Neurosci. Res., 62, 830-839.

Bhaskar, K., Shareef, M.M., Sharma, V.M., Shetty, A.P., Ramamohan, Y., Pant, H.C., Raju, T.R. \& Shetty, K.T. (2004) Co-purification and localization of Munc18-1 (p67) and Cdk5 with neuronal cytoskeletal proteins. Neurochem. Int., 44, 35-44.

Biederer, T. \& Sudhof, T.C. (2000) Mints as adaptors. Direct binding to neurexins and recruitment of munc18. J. Biol. Chem., 275, 39803-39806.

Brandon, E.P., Lin, W., D’Amour, K.A., Pizzo, D.P., Dominguez, B., Sugiura, Y., Thode, S., Ko, C.P., Thal, L.J., Gage, F.H. \& Lee, K.F. (2003) Aberrant patterning of neuromuscular synapses in choline acetyltransferase-deficient mice. J. Neurosci., 23, 539-549. 
Buffelli, M., Burgess, R.W., Feng, G., Lobe, C.G., Lichtman, J.W. \& Sanes, J.R. (2003) Genetic evidence that relative synaptic efficacy biases the outcome of synaptic competition. Nature, 424, 430-434.

Deitcher, D.L., Ueda, A., Stewart, B.A., Burgess, R.W., Kidokoro, Y. \& Schwarz, T.L. (1998) Distinct requirements for evoked and spontaneous release of neurotransmitter are revealed by mutations in the Drosophila gene neuronal-synaptobrevin. J. Neurosci., 18, 2028-2039.

Duxson, M.J. (1982) The effect of postsynaptic block on development of the neuromuscular junction in postnatal rats. J. Neurocytol., 11, 395-408.

Featherstone, D.E., Rushton, E. \& Broadie, K. (2002) Developmental regulation of glutamate receptor field size by nonvesicular glutamate release. Nat. Neurosci., 5, 141-146.

Gahwiler, B.H. (1984) Slice cultures of cerebellar, hippocampal and hypothalamic tissue. Experientia, 40, 235-243.

Gahwiler, B.H., Thompson, S.M., McKinney, R.A., Debanne, D. \& Robertson, R.T. (1998) Organotypic slice cultures of neural tissue. In Banker, G. \& Goslin, K. (eds), Culturing Nerve Cells. MIT press, Cambridge, pp. 461-498.

Hamabe, W., Fujita, R., Ueda, H., Washbourne, P., Thompson, P.M., Carta, M., Costa, E.T., Mathews, J.R., Lopez-Bendito, G., Molnar, Z., Becher, M.W., Valenzuela, C.F., Partridge, L.D., Wilson, M.C., Schoch, S., Deak, F., Konigstorfer, A., Mozhayeva, M., Sara, Y., Sudhof, T.C. \& Kavalali, E.T. (2003) Neuronal necrosis inhibition by insulin through protein kinase C-activation. J. Pharmacol. Exp. Ther., 307, 205-212.

Harrison, S.D., Broadie, K., van de Goor, J. \& Rubin, G.M. (1994) Mutations in the Drosophila Rop gene suggest a function in general secretion and synaptic transmission. Neuron, 13, 555-566.

Heeroma, J.H., Plomp, J.J., Roubos, E.W. \& Verhage, M. (2003) Development of the mouse neuromuscular junction in the absence of regulated secretion. Neuroscience, 120, 733-744.

Houenou, L.J., Pincon-Raymond, M., Garcia, L., Harris, A.J. \& Rieger, F. (1990) Neuromuscular development following tetrodotoxin-induced inactivity in mouse embryos. J. Neurobiol., 21, 1249-1261.

Jensen, F.E. \& Harris, K.M. (1989) Preservation of neuronal ultrastructure in hippocampal slices using rapid microwave-enhanced fixation. J. Neurosci. Meth., 29, 217-230.

Katz, L.C. \& Crowley, J.C. (2002) Development of cortical circuits: lessons from ocular dominance columns. Nat. Rev. Neurosci., 3, 34-42.

Katz, L.C. \& Shatz, C.J. (1996) Synaptic activity and the construction of cortical circuits. Science, 274, 1133-1138.

Khan, A.H., Thurmond, D.C., Yang, C., Ceresa, B.P., Sigmund, C.D. \& Pessin, J.E. (2001) Munc18c regulates insulin-stimulated glut4 translocation to the transverse tubules in skeletal muscle. J. Biol. Chem., 276, 4063-4069.

Lichtman, J.W. \& Colman, H. (2000) Synapse elimination and indelible memory. Neuron, 25, 269-278.

Lindholm, D., Carroll, P., Tzimagiogis, G. \& Thoenen, H. (1996) Autocrineparacrine regulation of hippocampal neuron survival by IGF-1 and the neurotrophins BDNF, NT-3 and NT-4. Eur. J. Neurosci., 8, 1452-1460.

Misgeld, T., Burgess, R.W., Lewis, R.M., Cunningham, J.M., Lichtman, J.W. \& Sanes, J.R. (2002) Roles of neurotransmitter in synapse formation: development of neuromuscular junctions lacking choline acetyltransferase. Neuron, 36, 635-648.

Naren, A.P., Nelson, D.J., Xie, W., Jovov, B., Pevsner, J., Bennett, M.K., Benos, D.J., Quick, M.W. \& Kirk, K.L. (1997) Regulation of CFTR chloride channels by syntaxin and Munc18 isoforms. Nature, 390, 302-305.
Pancrazio, J.J., Keefer, E.W., Ma, W., Stenger, D.A. \& Gross, G.W. (2001) Neurophysiologic effects of chemical agent hydrolysis products on cortical neurons in vitro. Neurotoxicology, 22, 393-400.

Roelandse, M., Welman, A., Wagner, U., Hagmann, J. \& Matus, A. (2003) Focal motility determines the geometry of dendritic spines. Neuroscience, 121, 39-49.

Saitoe, M., Schwarz, T.L., Umbach, J.A., Gundersen, C.B. \& Kidokoro, Y. (2001) Absence of junctional glutamate receptor clusters in Drosophila mutants lacking spontaneous transmitter release. Science, 293, 514-517.

Sanes, J.R. \& Lichtman, J.W. (1999) Development of the vertebrate neuromuscular junction. Annu. Rev. Neurosci., 22, 389-442.

Schoch, S., Deak, F., Konigstorfer, A., Mozhayeva, M., Sara, Y., Sudhof, T.C. \& Kavalali, E.T. (2001) SNARE function analyzed in synaptobrevin/VAMP knockout mice. Science, 294, 1117-1122.

Schulingkamp, R.J., Pagano, T.C., Hung, D. \& Raffa, R.B. (2000) Insulin receptors and insulin action in the brain: review and clinical implications. Neurosci. Biobehav. Rev., 24, 855-872.

Schulze, K.L. \& Bellen, H.J. (1996) Drosophila syntaxin is required for cell viability and may function in membrane formation and stabilization. Genetics, 144, 1713-1724.

Toonen, R.F. \& Verhage, M. (2003) Vesicle trafficking: pleasure and pain from SM genes. Trends Cell Biol., 13, 177-186.

Varoqueaux, F., Sigler, A., Rhee, J.S., Brose, N., Enk, C., Reim, K. \& Rosenmund, C. (2002) Total arrest of spontaneous and evoked synaptic transmission but normal synaptogenesis in the absence of Munc13-mediated vesicle priming. Proc. Natl Acad. Sci. USA, 99, 90379042.

Verhage, M., Maia, A.S., Plomp, J.J., Brussaard, A.B., Heeroma, J.H., Vermeer, H., Toonen, R.F., Hammer, R.E., van den Berg, T.K., Missler, M., Geuze, H.J. \& Sudhof, T.C. (2000) Synaptic assembly of the brain in the absence of neurotransmitter secretion. Science, 287, 864-869.

Vicario-Abejon, C., Owens, D., McKay, R. \& Segal, M. (2002) Role of neurotrophins in central synapse formation and stabilization. Nat. Rev. Neurosci., 3, 965-974.

Voets, T., Toonen, R.F., Brian, E.C., de Wit, H., Moser, T., Rettig, J., Sudhof, T.C., Neher, E. \& Verhage, M. (2001b) Munc18-1 promotes large dense-core vesicle docking. Neuron, 31, 581-591.

Wang, X., Butowt, R. \& von Bartheld, C.S. (2003) Presynaptic neurotrophin-3 increases the number of tectal synapses, vesicle density, and number of docked vesicles in chick embryos. J. Comp. Neurol., 458, 62-77.

Washbourne, P., Thompson, P.M., Carta, M., Costa, E.T., Mathews, J.R., Lopez-Bendito, G., Molnar, Z., Becher, M.W., Valenzuela, C.F., Partridge, L.D. \& Wilson, M.C. (2002) Genetic ablation of the t-SNARE SNAP-25 distinguishes mechanisms of neuroexocytosis. Nat. Neurosci., 5, 19-26.

Weisshaar, B., Doll, T. \& Matus, A. (1992) Reorganisation of the microtubular cytoskeleton by embryonic microtubule-associated-protein 2 (MAP2c). Development, 116, 1151-1161.

Yamada, M., Tanabe, K., Wada, K., Shimoke, K., Ishikawa, Y., Ikeuchi, T., Koizumi, S. \& Hatanaka, H. (2001) Differences in survival-promoting effects and intracellular signaling properties of BDNF and IGF-1 in cultured cerebral cortical neurons. J. Neurochem., 78, 940-951.

Zhao, H. \& Nonet, M.L. (2000) A retrograde signal is involved in activitydependent remodeling at a C. elegans neuromuscular junction. Development, 127, 1253-1266. 